\title{
Inorganic Nitrite as a Potential Therapy or Biomarker for Concussion
}

James H Silver*

Silver Medical, Inc. 45 Roosevelt Circle, Palo Alto, CA 94306, USA

*Corresponding author: Silver Medical, Inc. 45 Roosevelt Circle, Palo Alto, CA 94306, USA, Tel: 650-464-1759; E-mail: jim@silvermedicalinc.com

Received date: March 29, 2016; Accepted date: April 27, 2016; Published date: April 29, 2016

Copyright: (C) 2016 Silver $\mathrm{JH}$. This is an open-access article distributed under the terms of the Creative Commons Attribution License, which permits unrestricted use, distribution, and reproduction in any medium, provided the original author and source are credited.

\begin{abstract}
One of the hallmarks of concussion is a disturbance, typically a reduction, in cerebral blood flow. Studies have shown a rapid increase in nitric oxide within minutes following head injury, followed by a decline to below baseline within hours. This reduction in nitrite levels is closely linked to a reduction in cerebral blood flow. Inorganic nitrite has recently been shown to be a source of nitric oxide under conditions of ischemia or hypoxia, and has been shown to increase cerebral blood flow and to improve neurovascular coupling. Dietary nitrate has been shown to be converted to nitrite in the bloodstream. This review suggests that inorganic nitrite, and/or dietary nitrate, should be investigated for their potential in treating concussion symptoms.
\end{abstract}

Keywords: Concussion; Mild traumatic brain injury; Chronic traumatic encephalopathy; Nitrite; Nitrate; Cerebral blood flow

\section{Background}

Currently, there are as many as 3.8 million concussions per year [1]. Concussion (or mild traumatic brain injury, mTBI) has recently become an area of significant interest. Until recently, many coaches, athletes and parents had considered a concussion to be on roughly the same level as a bruise, which would heal itself within a few weeks and be without any serious long-term consequences. However, some individuals suffer from post-concussion syndrome (PCS) symptoms for months or longer, with as many as $15 \%$ of people with a history of mTBI still suffering from deficits a full one year after injury [2]. Postconcussion syndrome presents with symptoms such as headaches, dizziness, disturbances of senses, light and noise sensitivity, and various psychiatric symptoms, including depression, anxiety, and coping issues following mTBI or other head injury. In addition, it has been observed that repeated concussions or possibly even subconcussive head impacts may cause long term brain injury termed "chronic traumatic encephalopathy" (CTE) [3]. CTE is currently a post-mortem diagnosis which slows progress in the field.

\section{Concussion Diagnosis}

Not all researchers are currently using the same definition of concussion, but there are efforts underway to provide an evidencebased definition [4]. Currently, the diagnosis of acute concussion is subjective and usually involves the assessment of clinical symptoms, physical signs (e.g., loss of consciousness (LOC), amnesia), cognitive impairment (e.g., feeling like in a fog, slowed reaction times), neurobehavioral features (e.g., irritability) and sleep disturbance [5]. Football players and other athletes are good at playing through injuries, and doctors are under time pressure to make rapid decisions about return-to-play. Therefore it would be desirable to have objective diagnostics for concussion.

Although a multifaceted approach to sport-related concussion management is recommended (i.e., neuropsychological testing, balance or motor-ability assessment, and monitoring self-reported symptoms), clinicians may rely heavily on computerized neuropsychological testing (such as ImPACT) to determine the state of a concussed athlete and use these data in making return-to-play decisions. Variable test-retest reliability on computerized cognitive tests enhances the importance of the clinical examination and clinical judgment in the management of sport-related concussion. One review found that ImPACT had varying test-retest reliability on several metrics using different time frames for reassessment [6]. Another recent review of the ImPACT computerized neurocognitive assessment test found that although the convergent validity of ImPACT was supported, evidence of discriminant and predictive validity, diagnostic accuracy and responsiveness was inconclusive. The utility of the ImPACT test after acute symptom resolution was sparse. Many factors were found to influence the validity and utility of ImPACT scores [7].

The SCAT3 was developed for the sideline evaluation of potentially concussed athletes. Normative data and concussion cut off scores are not yet available for the SCAT3 [1]. However, one study found that 50 percent of a sample of collegiate athletes who sustained a diagnosed concussion (with athletic trainers present for all games and practices) did not experience an "immediate or near immediate" onset of symptoms [8].

When used on the day of injury, a retrospective study found that the Military Acute Concussion Evaluation (MACE) is a reliable and valid measure of cognitive dysfunction after mTBI (AUC $=0.71$ ) [9]. However, when administered more than 12 hours after the concussive injury, MACE lacked sufficient sensitivity and specificity to be clinically useful [10].

Biomechanics measurements such as force and acceleration have not been shown to correlate with concussion [11]. In spite of this, the use of helmet and mouthguard sensors to measure impact forces has increased dramatically in the past few years, demonstrating the need for a product to accurately detect concussions.

A blood test would be an ideal diagnostic for concussion, because it would minimize the possibility that an athlete would intentionally try to get a low baseline score so that they would not be removed from competition in the event of an actual concussion. 
There are several potential blood biomarkers for concussion including glial fibrillary acidic protein (GFAP), ubiquitin carboxyterminal hydrolase L1 (UCHL1), S100B, N-acetylaspartate (NAA), and others. These have been discussed in several excellent reviews [12-14] and will only be described briefly here. Break-down products of GFAP (GFAP-BDP) were found to be elevated in the serum within $1 \mathrm{~h}$ of mild or moderate TBI (AUC $=0.90)$. Serum UCHL1 has also been detected in patients with mTBI within $1 \mathrm{~h}$ of injury $(\mathrm{AUC}=0.87)$ S100B has a very high sensitivity $(>95 \%)$ but low specificity $(\sim 30 \%)$. Neuron-specific enolase (NSE) can be detected within $6 \mathrm{~h}$ of injury but has relatively low sensitivity (55\% in regard to neuropsychological outcome). $\mathrm{N}$-acetylaspartic acid (NAA) may be indicative of neuronal damage in diseases in addition to concussion such as amyotrophic lateral sclerosis (ALS), multiple sclerosis, vascular dementia, as well as traumatic brain injury (TBI). Other potential biomarkers include myelin basic protein (MBP) (sensitivity 44\%, specificity 96\%), microRNA, and the calpain-derived aII-spectrin N-terminal fragment (SNTF) [15]. Certain biomarkers are obtained from cerebrospinal fluid (CSF) rather than blood, such as neurofilament light polypeptide (NFL), limiting its potential utility at the sideline of a sports event.

\section{Concussion treatment}

The current standard of care for treating concussions is rest, followed by a gradual program of "return-to-activity" [5]. Hyperbaric oxygen therapy (HBOT) has been investigated, but failed clinical studies [16]. Critics of these studies argue that the control arm was inappropriate $[17,18]$, and that both groups received enhanced oxygen delivery, although at different doses, and the fact that results were equivalent in both groups merely demonstrates that we don't currently understand the proper dose. However, the cost of HBOT is not inconsequential, at roughly $\$ 5,000$ to $\$ 10,000$ for 40 treatment sessions.

Physical activity is restricted after concussion to improve recovery and to reduce risk for a second injury, and has broad support as the sole means to eliminate Second Impact Syndrome [19]. Athletes reporting concussion related symptoms well beyond the acute stage of injury may benefit from a progressively intensive exercise protocol [20]. Vestibular physical therapy for treatment of both balance and visual deficits following concussion has been shown to be beneficial. A Cochrane review concluded that there is moderate to strong evidence for efficacy of vestibular rehabilitation [21]. Following the acute recovery period, pharmacological interventions are often used offlabel, including neurostimulants such as Adderal for cognitive-fatigue, antidepressants for anxiety or mood disorders, and melatonin for sleep disturbances. One potential therapy that has been proposed for treatment of brain injury is nitrite delivery [22].

\section{CBF alteration following concussion}

Cerebral blood flow (CBF) decreases immediately following both moderate to severe TBIs and mTBIs, and it can remain depressed for extended durations [1]. A study of CBF in concussed youths (ages 11-15 years) found a statistically significant reduction in CBF in the concussion group as compared with controls (38 vs $48 \mathrm{~mL} / 100 \mathrm{~g}$ per minute; $\mathrm{p}=0.027)$. Improvement toward control values occurred in only $27 \%$ of the participants at 14 days and $64 \%$ at 30 days after concussion [23]. Thus cerebral blood flow can be reduced for over 30 days in sports-related concussions among youths. However, some reports show blood flow increasing in the acute phase after mTBI [24].

\section{Biochemical cascade and nitrite changes}

Immediately following a concussive injury, studies in rodents show the occurrence of an indiscriminate efflux of potassium and glutamate and an influx of calcium [1]. The release of excitatory amino acids following severe brain injury in humans has been observed using microdialysis probes [1]. In an effort to restore ionic and cellular homeostasis, ATP-requiring membrane ionic pumps begin to perform rapid glycolysis, resulting in a relative depletion of intracellular energy reserves, and an increase in ADP [25]. In very early phases, this increased demand for energy occurs in a setting of reduced cerebral blood flow, resulting in a mismatch between energy supply and demand. Excellent reviews of the post-concussion biochemical cascade and clinical sequelae such as the reduction in $\mathrm{CBF}$ have been reported elsewhere [13]

Following brain impact injury, NO levels show a rapid increase almost immediately in animal models. This increase in NO levels is the result of an immediate, massive depolarization of brain cells after concussion. The depolarization opens ionic channels, allowing calcium and other ions to flow down their concentration gradients and disrupt cell membrane potential [1]. This influx of calcium ions can upregulate constitutive nitric oxide synthases (eNOS and nNOS) [26-28]. Using NO-specific electrodes placed directly in brain parenchyma, Cherian [29] found an immediate increase in NO levels of approximately 75 $\mathrm{nM}$ after traumatic brain injury in rats, which dropped to below baseline within less than 15 minutes. Wang [30] found the same rapid increase in $\mathrm{NO}$ in less than $5 \mathrm{~min}$, dropping to baseline within 30 minutes using continuous microdialysis measurements coupled with online chemiluminescence. Wada also found that following fluid percussion injury in rats, cNOS activity was upregulated to more than $200 \%$ of contralateral values within 5 minutes, with nitrite and nitrate showing a parallel response [31,32]. Sakamoto [33] and Rao [34] demonstrated a nearly 2.5 -fold increase in the concentration of nitrite and nitrate after weight-drop injury within 5-10 minutes.

\section{Methods}

The purpose of this animal study was to provide preliminary proofof-concept that changes in nitrite following blast injury could be measured in the physiological regime in real time, thus laying the groundwork for future real-time studies on nitrite changes in concussion. This method could ultimately lead to an easy-to-use, clinically useful tool, something that was not achieved by previous investigators who placed electrodes in brain tissue, or used laboratory methods that are too slow to be of value in return-to-play decisions in a sports setting. As such, it was too small $(n=1)$ to meet the RIGOR criteria [35,36], and does not include blinding of the study, randomization of treatment groups, power analysis, control groups, or statistical analysis.

This study was performed at PMI Preclinical (San Carlos, CA) and approved by their IACUC committee. All animal care was performed according to PMI standard operating procedures. A $60 \mathrm{~kg}$ swine was anesthetized with $2.5 \%$ isoflurane to achieve a deep plane of anesthesia using standard anesthesiology apparatus to deliver inhalation anesthetics. The animal was placed in lateral recumbency and immobilized firmly on a table. The head of the animal was capable of movement. The animal was monitored for blood oxygen saturation and electrocardiogram (ECG). Venous access was established percutaneously via the jugular vein for plasma nitrite monitoring, and the animal was heparinized. Plasma nitrite monitoring was performed 
Page 3 of 7

continuously as previously described [37]. Monitoring began after the animal was deeply anesthetized for approximately 10 minutes prior to firing of an air gun, and for approximately 30 minutes afterward. The air gun (Model MBTB-25 Heavy Duty Tennis Ball Cannon, American Air Cannons, San Diego, CA) had a 2.5 inch diameter barrel and was pressurized to $100 \mathrm{psi}$. The air gun was positioned with the barrel perpendicular to and centered between the ears and eyes of the swine with the barrel opening $5 \mathrm{~cm}$ from the top of the skull, and the gun was fired. After the blast, the animal was monitored for an additional 30 minutes, and was then euthanized according to PMI standard operating procedures.

\section{Results}

Figure 1 shows the change in plasma nitrite for approximately 28 minutes following blast injury. The nitrite monitoring instrument had a 5 minute lag time under the conditions used in this study. At approximately 11 minutes after the blast injury (resulting in the measurement of a biological event that occurred 6 minutes after the blast) there was a large, steady increase in nitrite to approximately 340 $\mathrm{nM}$ above baseline within an additional 8 minutes (19 minutes total). In comparison, plasma nitrite levels in humans typically range from approximately 100 to $400 \mathrm{nM}$ [38]. After the first 19 minutes, nitrite levels began to decline for the remainder of the monitoring period. This change is consistent with that previously reported by others as described above, and is approximately ten times faster than that observed following consumption of beet juice or high nitrate fluids [39].

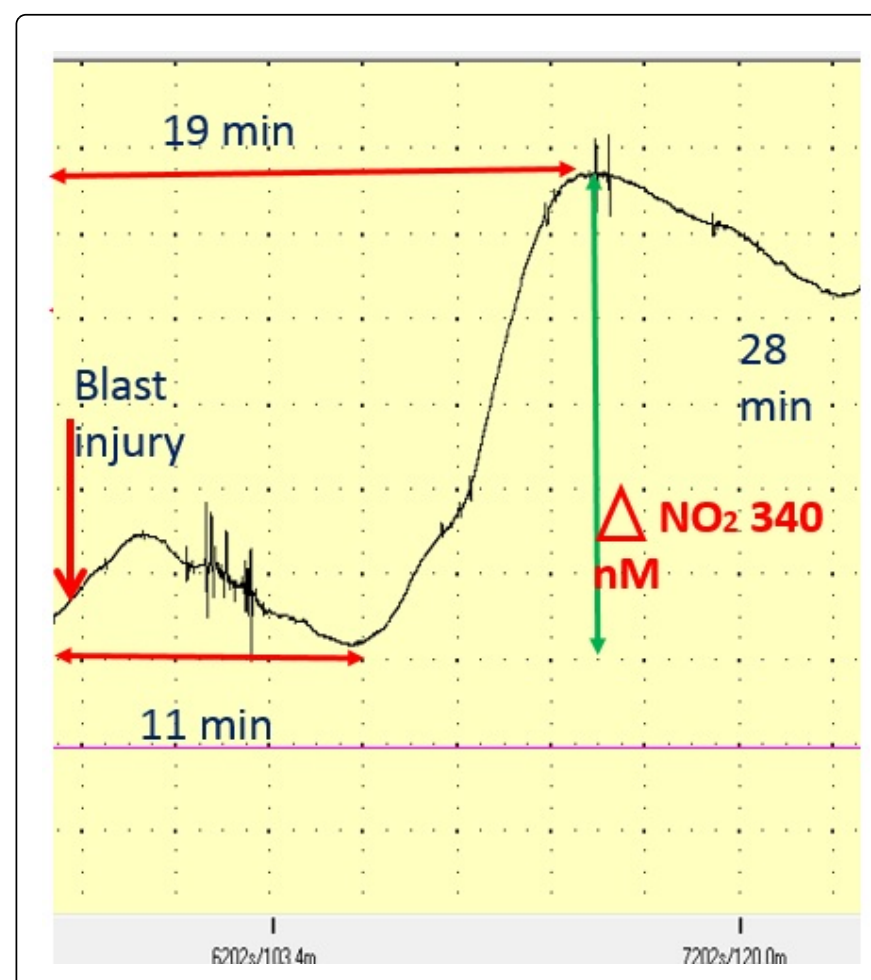

Figure 1: Trace showing nitrite changes following blast injury in a porcine model. Scale (horizontal $=200 \mathrm{sec} /$ division, vertical $=65 \mathrm{nM}$ nitrite/division)

\section{Discussion}

While clearly limited in sample size, this example study, taken together with previously published research on changes in nitric oxide following head injury, suggests that nitrite could be a potential biomarker for concussion, if multiple measurements could be taken between approximately 5 and 15 minutes following injury. Nitrite would have the most potential utility in a sports setting where time is critical to return-to-play decision making, and the need for rapid diagnostics is greatest, but would be less useful in delayed care settings. A diagnostic that would take more than about 15 minutes would not be useful in a typical sports setting. Such rapid changes in plasma nitrite might be useful for sporting events where the timing could be easily established, and measurements could be performed by an athletic trainer. In addition, the decline in nitrite levels between 15 minutes and one hour might be useful in the emergency room. Also, while athletes may consume nitrates in order to improve sports performance, the rate of change of nitrite following concussion was found to be 10 times faster in this animal study than following consumption of beet juice [39]. A key advantage of nitrite as a biomarker is that it is extremely rapid, while other protein biomarkers are generally slower. In the current study, a continuous blood draw was obtained, but this approach could be easily adapted to a finger-stick monitor, similar to many blood glucose meters. Nitrite levels could be tested using a hand-held version of this instrument, both before and after standard assessments such as SCAT3 [40] thus allowing appropriate timing for a change in nitrite to occur. However, there are no published data available to indicate of whether or not a change in nitrite levels might be observable following sub-concussive impacts.

Nitric oxide (NO) plays an important role in control of cerebral blood flow. After the initial peak in NO following brain injury, there can be a period of relative deficiency in NO. This period of low NO levels is associated with a low cerebral blood flow (CBF) [41]. NO levels correlate with cerebral blood flow in fMRI [42]. Reduced NO levels occur following TBI, and are correlated with ischemia [43]. In normal subjects studies show that whole-blood nitrite levels are constant with a coefficient of variation of $<8 \%[24,44]$.

\section{Nitrite in Ischemia}

While concussion itself is not an ischemic event, concussion is a subset of traumatic brain injury (TBI). Secondary ischemia is a major concern following TBI, and the fact that cerebral blood flow is frequently reduced for prolonged periods suggests that nitrite could be an effective therapy for treating concussion.

Nitrite has been shown to be a source of nitric oxide under ischemic conditions. Recently, an alternative pathway for generation of NO has been discovered [45]. The anion nitrite was previously considered physiologically inert, a stable end product of nitric oxide (NO) metabolism, and a biomarker for NO activity. Nitrite has been shown to be a circulating storage pool for NO [46] that the body can rapidly activate when needed. Rapid conversion of nitrite to NO can occur under ischemic conditions (low $\mathrm{pH}$, low partial pressure of oxygen $(\mathrm{pO} 2)$ ) [47]. There are several enzymes which may act to reduce nitrite to NO, including deoxyhemoglobin, deoxymyoglobin, xanthine oxoreductase (XOR), neuroglobin, eNOS, and components of the mitochondrial electron transport chain [48]. The deoxygenated state of hemoglobin has been characterized as an allosterically regulated nitrite reductase. The different nitrite reductase "enzyme" systems operate along a range of physiological and pathological hypoxia, with 
hemoglobin reducing nitrite at an oxygen tension from $60 \mathrm{~mm} \mathrm{Hg}$ down to $20 \mathrm{~mm} \mathrm{Hg}$, myoglobin active below $4 \mathrm{~mm} \mathrm{Hg}$, and xanthine oxoreductase and acidic reduction reducing nitrite at zero oxygen and low $\mathrm{pH}[38,49]$. This allows for graded nitrite reduction to NO along the circulating and metabolic oxygen gradient [50]. In addition, as $\mathrm{pH}$ decreases, the rate of the reaction increases [51]. Maximal physiological dilatation via this mechanism is proposed to occur at around 50\% hemoglobin oxygen saturation [52]. Conversion of nitrite to NO by deoxyhemoglobin can occur in as little as 30 seconds to several minutes [53].

NO generated by nitric oxide synthases (NOS) during normoxia may be chemically stored in a nitrite reservoir and re-generated during hypoxia and ischemia when oxygen-dependent NOS function is limited, and in areas in which increased blood flow would be desirable $[54,55]$. Nitrite represents the largest known source of bioavailable NO in the circulation, and can be considered an ischemic NO reservoir. There is an oxygen-dependent balance between NO and nitrite centered on hemoglobin in red blood cells. There may also be alternative oxidative signaling pathways for nitrite under normoxic conditions [56].

\section{Nitrite and neurovascular coupling}

Neurovascular coupling links neuronal oxygen demand to cerebral blood flow. Nitric oxide is a potent vasodilator, and NO production plays an important role in neurovascular coupling. Nitrite has also been shown to play a role in neurovascular coupling, and can be efficiently converted into $\mathrm{NO}$ and utilized to support normal cerebrovascular physiology. Following the initial uncoupling of neuronal and hemodynamic responses to somatosensory stimulation, Piknova et al. found that nitrite at its physiological concentration fully recovered neurovascular coupling to its original magnitude [57]. In subjects with elevated dietary nitrate, a faster and smaller MRI-BOLD response, with less variation across local cortex, was observed which is consistent with an enhanced hemodynamic coupling [58]. Wightman et al. found that single doses of dietary nitrate could modulate the CBF response to cognitive task performance and potentially improve performance [59]. These studies suggest that dietary nitrate may be a potential way to affect key properties of neurovascular coupling.

\section{Nitrite and oxidative injury}

In addition to the mTBI-induced metabolic crisis, various pathways result in oxidative damage following mTBI [1]. Direct measurement of reactive oxygen species in closed-head mouse model of traumatic brain injury has been reported [60]. Reactive oxygen species (ROS) and reactive nitrogen species can generate hydroxyl radicals $(\bullet \mathrm{OH})$ and peroxynitrite (ONOO-), which can cause damage to proteins, lipids, and DNA [1]. Nitrite administration has been shown to reduce damage from ROS [61].

\section{Nitrite as a potential therapeutic agent}

Nitrite is currently only approved as an antidote to cyanide poisoning [62], but is being investigated as a therapy for several conditions where ischemia or hypoxia is of concern. Potential concerns with nitrite therapy are that it can affect blood pressure or cause methemoglobinemia [63], so it requires close monitoring. For example, nitrite is under investigation for prevention of reperfusion injury associated with myocardial infarction. Comparing outcomes in heart attack (STEMI) patients receiving nitrite therapy in addition to standard therapy (angioplasty with stenting) vs. standard therapy alone, Jones et al. [64] have recently shown a statistically significant improvement in adverse event rates (death, heart attack, stroke) at oneyear follow-up.

Nitrate based agents such as nitroglycerin, sodium nitroprusside and isosorbide dinitrate, are generally avoided in patients with acute head injury because of the potential to increase intracranial pressure (ICP) [65]. However, these agents release NO systemically, while plasma nitrite is preferentially reduced to NO locally at sites of hypoxia or ischemia, which permits the use of nitrite as an inert delivery vehicle while avoiding issues associated with systemic delivery of NOdonating agents. Sodium nitrite infusions in healthy humans did not produce any clinical signs of increased intracranial pressure, such as headache or nausea, consistent with the lack of dilation in normal cerebral vasculature [55].

This potential has stimulated substantial research into the use of nitrite as a therapeutic agent for the prevention and reversal of cerebral vasospasm after subarachnoid hemorrhage (SAH) among other conditions. Statins, which have been shown to elevate NO via an eNOS pathway [66], and NO donors such as sodium nitroprusside (SNP) and nitroglycerin (NTG) have been studied clinically and have shown limited success in treating SAH [67]. The normal eNOS pathway for NO production is not effective under conditions of ischemia and hypoxia such as vasospasm. Major drawbacks with SNP and NTG in treating SAH were nonselective vasodilation, short-lasting effects with rebound phenomenon, drug tolerance, and side effects including systemic hypotension, nausea, vomiting, and increased intracranial pressure [68]. Continuous infusions of nitrite have been shown to prevent vasospasm in a primate model of SAH [69]. Based on these results, a Phase II clinical trial studying the effect of nitrite on SAH was performed [70] and did not report any adverse effects on ICP. While the underlying pathology of SAH reduces endogenous nitrite resulting in vasospasm, the pathology may be effectively reversed by exogenous nitrite administration. Clinical trials are currently underway to investigate the use of nitrite therapy for reversal of vasospasm in the treatment of SAH [71].

Nitrite infusions have been shown to increase cerebral blood flow, and reduce cerebrovascular resistance [72]. A safety study investigating the administration of nitrite in normal volunteers [41] has demonstrated the maximum safe levels of nitrite administration. The optimal delivery route and dosage of nitrates and nitrites, as well as pharmacokinetics remain to be determined in mTBI patients.

In mTBI cases in which CBF is elevated in the acute phase [24], nitrite would potentially be of less therapeutic utility, although elevated nitrite may be indicative of inflammatory processes and thus suggestive of other therapies. Therefore it could be important to measure a patient's nitrite level following a concussion, and to periodically monitor nitrite levels following administration of nitrite therapy.

\section{Nitrate vs. nitrite therapies}

As a possible alternative to nitrite therapy, nitrate therapy could be considered. Nitrate has been shown to be converted to nitrite via nitrate reductase enzymes which are found in commensal bacteria in the mouth or intestines [73]. These bacterial nitrate reductases contribute significantly to the endogenous nitrite pool. Thus, some investigators have used nitrate-rich foods such as beet juice to deliver nitrite therapies. Dietary nitrate has been shown to increase regional 
cerebral blood flow in adults using MRI [74]. Nitrate is a potentially safer, albeit slower-acting therapeutic. The current standard of care for treatment of brain injuries such as stroke is to treat the injury as soon as possible, preferably within a 3-hour window [75]. This suggests that direct administration of nitrite would be preferred method of treatment. By contrast dietary nitrate takes approximately 2 hours to be converted by bacteria in the mouth to nitrite [39] and thus may allow brain injury to continue during this period.

\section{Alternative Therapies}

Administration of L-arginine, a nitric oxide synthase (NOS) substrate, in rodent TBI models results in the restoration of $\mathrm{CBF}$ and NO levels to near baseline and decreases neurologic injury [41]. Sildenafil $\left(\right.$ Viagra $\left.^{\circ}\right)$ (an inhibitor of cGMP-specific phosphodiesterase type 5) and nitrite in combination produce additive beneficial effects during acute pulmonary embolism [76], and may also be useful for concussion therapy. Since glycolysis is accelerated shortly after concussion, administration of glucose could also be considered, along with frequent blood glucose measurements during the acute period. Nimodipine, a calcium channel blocker, was studied in 224 patients with concussion, with half getting the drug and the other half serving as controls. The nimodipine group showed reduced vasospasm and improved symptom recovery [77]. This suggests that a method (such as nitrite therapy) to improve cerebral blood flow post-injury may result in improved patient outcomes in concussion.

\section{Summary}

In order to validate nitrite as a diagnostic, the next steps would include using multiple single-point measurements in the 5-15 minute post-injury time window using a handheld finger-stick meter to make the measurements. Nitrite measurements could also be a useful tool to track the response of concussion patients to nitrite therapy, ensuring that the appropriate therapeutic level is being administered.

Administration of nitrite or nitrate may improve cerebral blood flow and neurovascular coupling following concussion, but basic questions remain such as the appropriate dosage, the timing and duration of dosing, and the timing of patient return-to-activity. These answers will no doubt vary from patient to patient, depending on the specifics of their injury. One way to answer these questions would be to measure cerebral blood flow by methods such as MRI, Transcranial Doppler, or other flow measurement techniques. However, these methods are costly and impractical to use on a frequent basis to determine if a patient is recovering from a concussion. Today, most methods for measuring nitrite in blood are either insufficiently accurate in the physiological regime or inconveniently slow laboratory methods such as ozone-chemiluminescence, although more rapid methods are under development [78].

Increasing $\mathrm{CBF}$ by nitrite or nitrate therapy has the potential to improve concussion symptoms and shorten recovery time, but it remains to be seen whether such an approach could ultimately reduce the risk of CTE. A reduction in cerebral blood flow is not the only source of brain injury following concussion. Ultrastructural studies of axons show mechanical breakage and buckling of microtubules at the time of injury, which can be detected using diffusion tensor imaging (DTI) [79]. Thus while nitrite therapy may relieve concussion symptoms related to reduced CBF, it may not alleviate the mechanical injury to axons, and thus may not prevent longer term brain injury such as CTE. By increasing CBF with nimodipine, Xiao et al. [77] showed that concussion symptoms were improved. By analogy with ischemic stroke, which can only be successfully treated within a limited time window, the more quickly CBF is restored to normal, the greater the probability of a successful outcome.

Given the urgent need to address concussion, the lack of effective treatment strategies, and the potential ease of use and costeffectiveness of nitrite or nitrate administration, further research in this area is justified.

\section{Acknowledgment}

This research was funded by Silver Medical, Inc., and PMI Preclinical. The author holds interest in Silver Medical Inc. with patents for measuring nitrite in blood.

\section{References}

1. (2013) Institute of Medicine (IOM) and National Research Council (NRC). Sports-related concussions in youth: Improving the science, changing the culture. The National Academies Press, Washington DC, USA.

2. Daneshvar DH, Riley DO, Nowinski CJ, McKee AC, Stern RA, et al. (2011) Long-term consequences: effects on normal development profile after concussion. Phys Med Rehabil Clin N Am 22: 683-700, ix.

3. Omalu BI, DeKosky ST, Minster RL, Kamboh MI, Hamilton RL, et al. (2005) Chronic traumatic encephalopathy in a National Football League player. Neurosurgery 57: 128-134.

4. Carney N, Ghajar J, Jagoda A, Bedrick S, Davis-OÊ $1 / 4$ Reilly C, et al. (2014) Concussion guidelines step 1: systematic review of prevalent indicators. Neurosurgery 75 Suppl 1: S3-15.

5. McCrory P, Meeuwisse WH, Aubry M, Cantu B, Dvorák J, et al. (2013) Consensus statement on concussion in sport: the 4th International Conference on Concussion in Sport held in Zurich, November 2012. Br J Sports Med 47: 250-258.

6. Resch J, Driscoll A, McCaffrey N, Brown C, Ferrara MS, et al. (2013) ImPact test-retest reliability: reliably unreliable? J Athl Train 48: 506-511.

7. Alsalaheen B, Stockdale K, Pechumer D, Broglio SP (2016) Validity of the Immediate Post Concussion Assessment and Cognitive Testing (ImPACT). Sports Med.

8. Duhaime AC, Beckwith JG, Maerlender AC, McAllister TW, Crisco JJ, et al. (2012) Spectrum of acute clinical characteristics of diagnosed concussions in college athletes wearing instrumented helmets. Journal of Neurosurgery 117:1092-1099.

9. McCrea M, Guskiewicz K, Doncevic S, Helmick K, Kennedy J, et al. (2014) Day of injury cognitive performance on the Military Acute Concussion Evaluation (MACE) by U.S. military service members in OEF/OIF. Mil Med 179: 990-997.

10. Coldren RL, Kelly MP, Parish RV, Dretsch M, Russell ML (2010) Evaluation of the Military Acute Concussion Evaluation for use in combat operations more than 12 hours after injury. Mil Med 175: 477-481.

11. Forbes JA, Awad AJ, Zuckerman S, Carr K, Cheng JS (2012) Association between biomechanical parameters and concussion in helmeted collisions in American football: a review of the literature. Neurosurg Focus 33: 1-6.

12. Jeter CB, Hergenroeder GW, Hylin MJ, Redell JB, Moore AN, et al. (2013) Biomarkers for the diagnosis and prognosis of mild traumatic brain injury/concussion. J Neurotrauma 30: 657-670.

13. Zetterberg H, Smith DH, Blennow K (2013) Biomarkers of mild traumatic brain injury in cerebrospinal fluid and blood. Nat Rev Neurol 9: 201-210.

14. Dambinova SA, Sowell RL, Maroon JC (2013) Gradual Return to Play: Potential Role of Neurotoxicity Biomarkers in Assessment of Concussions Severity. J Mol Biomark Diagn S3: 003. 
15. Siman R, Shahim P, Tegner Y, Blennow K, Zetterberg H, et al. (2014) Serum SNTF Increases in Concussed Professional Ice Hockey Players and Relates to the Severity of Post-Concussion Symptoms. J Neurotrauma 32:1294-300.

16. Wolf G, Cifu D, Baugh L, Carne W, Profenna L (2012) The effect of hyperbaric oxygen on symptoms after mild traumatic brain injury. J Neurotrauma 29: 2606-2612.

17. Hu Q, Manaenko A, Guo Z, Huang L, Tang J, et al. (2015) Hyperbaric oxygen therapy for post concussion symptoms: issues may affect the results. Med Gas Res 5: 10.

18. Harch PG (2013) Hyperbaric oxygen therapy for post-concussion syndrome: contradictory conclusions from a study mischaracterized as sham-controlled. J Neurotrauma 30: 1995-1999.

19. Bruce DA, Alavi A, Bilaniuk L, Dolinskas C, Obrist W, et al. (1981) Diffuse cerebral swelling following head injuries in children: the syndrome of "malignant brain edema". J Neurosurg 54: 170-178.

20. Broglio SP, Collins MW, Williams RM, Mucha A, Kontos AP (2015) Current and emerging rehabilitation for concussion: a review of the evidence. Clin Sports Med 34: 213-231.

21. Hillier SL, Hollohan V (2007) Vestibular rehabilitation for unilateral peripheral vestibular dysfunction. Cochrane Database Syst Rev CD005397.

22. Garry PS, Ezra M, Rowland MJ, Westbrook J, Pattinson KT (2015) The role of the nitric oxide pathway in brain injury and its treatment from bench to bedside. Exp Neurol 263: 235-243.

23. Maugans TA, Farley C, Altaye M, Leach J, Cecil KM (2012) Pediatric sports-related concussion produces cerebral blood flow alterations. Pediatrics 129: 28-37.

24. Doshi H, Wiseman N, Liu J, Wang W, Welch RD, et al. (2015) Cerebral hemodynamic changes of mild traumatic brain injury at the acute stage. PLoS One 10: e0118061.

25. Giza CC, Hovda DA (2014) The new neurometabolic cascade of concussion. Neurosurgery 75 Suppl 4: S24-33.

26. Sessa WC (2004) eNOS at a glance. J Cell Sci 117: 2427-2429.

27. Liu PK, Robertson CS, Valadka A (2002) The association between neuronal nitric oxide synthase and neuronal sensitivity in the brain after brain injury. Ann N Y Acad Sci 962: 226-241.

28. Müller U, Bicker G (1994) Calcium-activated Release of Nitric Oxide and Cellular Distribution of Nitric Oxide-Synthesizing Neurons in the Nervous System of the Locust" J. Neuroscience, December, 74: 7521-7528.

29. Cherian L, Goodman JC, Robertson CS (2000) Brain nitric oxide changes after controlled cortical impact injury in rats. J Neurophysiol 83: 2171-2178.

30. Wang J, Lu M, Yang F, Zhang X, Baeyens WRG, et al. (2001) Microdialysis with on-line chemiluminescence detection for the study of nitric oxide release in rat brain following traumatic injury. Analytica Chimica Acta 428: 173-181.

31. Wada K, Chatzipanteli K, Busto R, Dietrich WD (1998) Role of nitric oxide in traumatic brain injury in the rat. J Neurosurg 89: 807-818.

32. Wada K, Chatzipanteli K, Busto R, Dietrich WD (1999) Effects of LNAME and 7-NI on NOS catalytic activity and behavioral outcome after traumatic brain injury in the rat. J Neurotrauma 16: 203-212.

33. Sakamoto KI, Fujisawa H, Koizumi H, Tsuchida E, Ito H, et al. (1997) Effects of mild hypothermia on nitric oxide synthesis following contusion trauma in the rat. J Neurotrauma 14: 349-353.

34. Rao AM, Dogan A, Hatcher JF, Dempsey RJ (1998) Fluorometric assay of nitrite and nitrate in brain tissue after traumatic brain injury and cerebral ischemia. Brain Res 793: 265-270.

35. Landis SC, Amara SG, Asadullah K, Austin CP, Blumenstein R, et al. (2012) A call for transparent reporting to optimize the predictive value of preclinical research. Nature 490: 187-191.

36. Lapchak PA (2013) Recommendations and practices to optimize stroke therapy: developing effective translational research programs. Stroke 44 841-843.
37. Silver JH, Lapchak PA (2011) Continuous monitoring of changes in plasma nitrite following cerebral ischemia in a rabbit embolic stroke model. Transl Stroke Res 2: 218-226.

38. Kleinbongard P, Dejam A, Lauer T, Jax T, Kerber S, et al. (2006) Plasma nitrite concentrations reflect the degree of endothelial dysfunction in humans. Free Radic Biol Med 40: 295-302.

39. Wylie LJ, Kelly J, Bailey SJ, Blackwell JR, Skiba PF, et al. (2013) Beetroot juice and exercise: pharmacodynamic and dose-response relationships. J Appl Physiol (1985) 115: 325-336.

40. (2013) SCAT3. Br J Sports Med 47: 259.

41. Cherian L, Hlatky R, Robertson CS (2004) Nitric oxide in traumatic brain injury. Brain Pathol 14: 195-201.

42. Bitner BR, Brink DC, Mathew LC, Pautler RG, Robertson CS (2010) Impact of arginase II on CBF in experimental cortical impact injury in mice using MRI. J Cereb Blood Flow Metab 30: 1105-1109.

43. Hlatky R, Goodman JC, Valadka AB, Robertson CS (2003) Role of nitric oxide in cerebral blood flow abnormalities after traumatic brain injury. J Cereb Blood Flow Metab 23: 582-588.

44. Dejam A, Hunter CJ, Pelletier MM, Hsu LL, Machado RF, et al. (2005) Erythrocytes are the major intravascular storage sites of nitrite in human blood. Blood 106: 734-739.

45. Cosby K, Partovi KS, Crawford JH, Patel RP, Reiter CD, et al. (2003) Nitrite reduction to nitric oxide by deoxyhemoglobin vasodilates the human circulation. Nat Med 9: 1498-1505.

46. Hill BG, Dranka BP, Bailey SM, Lancaster JR Jr, Darley-Usmar VM (2010) What part of NO don't you understand? Some answers to the cardinal questions in nitric oxide biology. J Biol Chem 285: 19699-19704.

47. Gladwin MT, Schechter AN (2004) NO contest: nitrite versus S-nitrosohemoglobin. Circ Res 94: 851-855.

48. Tiso M, Tejero J, Basu S, Azarov I, Wang X, et al. (2011) Human neuroglobin functions as a redox-regulated nitrite reductase. J Biol Chem 286: 18277-18289.

49. Shiva S, Sack MN, Greer JJ, Duranski M, Ringwood LA, et al. (2007) Nitrite augments tolerance to ischemia/reperfusion injury via the modulation of mitochondrial electron transfer. J Exp Med 204: 2089-2102.

50. Dezfulian C, Raat N, Shiva S, Gladwin MT (2007) Role of the anion nitrite in ischemia-reperfusion cytoprotection and therapeutics. Cardiovasc Res 75: 327-338.

51. Shiva S (2010) Mitochondria as metabolizers and targets of nitrite. Nitric Oxide 22: 64-74

52. Rogers SC, Khalatbari A, Datta BN, Ellery S, Paul V, et al. (2007) NO metabolite flux across the human coronary circulation. Cardiovasc Res 75: 434-441.

53. Crawford JH, Isbell TS, Huang Z, Shiva S, Chacko BK, et al. (2006) Hypoxia, red blood cells, and nitrite regulate NO-dependent hypoxic vasodilation. Blood 107: 566-574.

54. Hollenberg SM, Cinel I (2009) Bench-to-bedside review: nitric oxide in critical illness--update 2008. Crit Care 13: 218.

55. Pluta RM, Oldfield EH, Bakhtian KD, Fathi AR, Smith RK, et al. (2011) Safety and feasibility of long-term intravenous sodium nitrite infusion in healthy volunteers. PLoS One 6: e14504.

56. Wang L, Frizzell SA, Zhao X, Gladwin MT (2012) Normoxic Cyclic GMPindependent Oxidative Signaling by Nitrite Enhances Airway Epithelial Cell Proliferation and Wound Healing. Nitric Oxide 26: 203-210.

57. Piknova B, Kocharyan A, Schechter AN, Silva AC (2011) The role of nitrite in neurovascular coupling. Brain Res 1407: 62-68.

58. Aamand R, Dalsgaard T, Ho YC, Møller A, Roepstorff A, et al. (2013) A NO way to BOLD? Dietary nitrate alters the hemodynamic response to visual stimulation. Neuroimage 83: 397-407.

59. Wightman EL, Haskell-Ramsay CF, Thompson KG, Blackwell JR, Winyard PG, et al. (2015) Dietary nitrate modulates cerebral blood flow parameters and cognitive performance in humans: A double-blind, placebo-controlled, crossover investigation. Physiol Behav 149:149-158. 
Citation: Silver JH (2016) Inorganic Nitrite as a Potential Therapy or Biomarker for Concussion. J Neurol Neurophysiol 7: 370 . doi: $10.4172 / 2155-9562.1000370$

Page 7 of 7

60. Roth TL, Nayak D, Atanasijevic T, Koretsky AP, Latour LL, et al. (2014) Transcranial amelioration of inflammation and cell death after brain injury. Nature 505: 223-228.

61. Omar SA, Webb AJ, Lundberg JO, Weitzberg E (2015) Therapeutic effects of inorganic nitrate and nitrite in cardiovascular and metabolic diseases. J Intern Med 279: 315-336.

62. Marraffa JM, Cohen V, Howland MA (2012) Antidotes for toxicological emergencies: a practical review. Am J Health Syst Pharm 69: 199-212.

63. CHEN KK, ROSE CL (1952) Nitrite and thiosulfate therapy in cyanide poisoning. J Am Med Assoc 149: 113-119.

64. Jones DA, Pellaton C, Velmurugan S, Rathod KS, Andiapen M, et al. (2015) Randomized phase 2 trial of intracoronary nitrite during acute myocardial infarction. Circ Res 116: 437-447.

65. Golan DE (2008) Principles of Pharmacology: The pathophysiologic basis of drug therapy (2nd edn.) Lippincott, Wilkins and Williams, Baltimore, NY, London.

66. Förstermann U, Sessa WC (2012) Nitric oxide synthases: regulation and function. Eur Heart J 33: 829-837, 837a-837d.

67. Kirkpatrick PJ, Turner CL, Smith C, Hutchinson PJ, Murray GD (2014) Simvastatin in aneurysmal subarachnoid haemorrhage (STASH): multicentre randomised phase 3 trial. Lancet Neurol 13: 666-675.

68. Fathi AR, Pluta RM, Bakhtian KD, Qi M, Lonser RR (2011) Reversal of cerebral vasospasm via intravenous sodium nitrite after subarachnoid hemorrhage in primates. J Neurosurg 115: 1213-1220.

69. Pluta RM, Dejam A, Grimes G, Gladwin MT, Oldfield EH (2005) Nitrite infusions to prevent delayed cerebral vasospasm in a primate model of subarachnoid hemorrhage. JAMA 293: 1477-1484.

70. Oldfield EH, Loomba JJ, Monteith SJ, Crowley RW, Medel R, et al. (2013) Safety and pharmacokinetics of sodium nitrite in patients with subarachnoid hemorrhage: a phase IIa study. J Neurosurg 119: 634-641.
71. (2016) Intravenous Nitrite Infusion for Reversal of Cerebral Vasospasm After Subarachnoid Hemorrhage. ClinicalTrials.gov.

72. Rifkind JM, Nagababu E, Barbiro-Michaely E, Ramasamy S, Pluta RM, et al. (2007) Nitrite infusion increases cerebral blood flow and decreases mean arterial blood pressure in rats: a role for red cell NO. Nitric Oxide 16: 448-456.

73. Webb AJ, Patel N, Loukogeorgakis S, Okorie M, Aboud Z, et al. (2008) Acute blood pressure lowering, vasoprotective, and antiplatelet properties of dietary nitrate via bioconversion to nitrite. Hypertension 51: 784-790.

74. Presley TD, Morgan AR, Bechtold E, Clodfelter W, Dove RW, et al. (2011) Acute effect of a high nitrate diet on brain perfusion in older adults. Nitric Oxide 24: 34-42.

75. (1995) Tissue Plasminogen Activator for Acute Ischemic Stroke. N Engl J Med 333: 1581-1587.

76. Dias-Junior CA, Montenegro MF, Florencio BC, Tanus-Santos JE (2008) Sildenafil Improves the Beneficial Haemodynamic Effects of Intravenous Nitrite Infusion during Acute Pulmonary Embolism. Basic Clin Pharmacol Toxicol 103: 374-379.

77. Xiao X, Guo X, Wang D, Xue G (2002) Mechanism and treatment principle for cerebral vessel spasm caused by concussion. Chin J Traumatol 5: 380-384.

78. Silver JH (2011) Nitrite and Nitric Oxide as Potential Diagnostic Markers in Acute Vascular Diseases. J Neurol Neurophysiol S1.

79. Tang-Schomer MD, Patel AR, Baas PW, Smith DH (2010) Mechanical breaking of microtubules in axons during dynamic stretch injury underlies delayed elasticity, microtubule disassembly, and axon degeneration. FASEB J 24: 1401-1410. 